\title{
O TEMPO PARA REPENSAR É AGORA: CONSIDERAÇÕES SOBRE A PANDEMIA DO NOVO CORONAVÍRUS (COVID-19)
}

\section{TIME TO RETHINK IS NOW: PANDEMIC CONSIDERATIONS OF THE NEW CORONAVIRUS (COVID-19)}

\author{
Taiane Aparecida Ribeiro Nepomoceno ${ }^{1}$ \\ ORCID iD https://orcid.org/0000-0003-3291-4221 \\ Terezinha Corrêa Lindino ${ }^{2}$ \\ ORCID iD https://orcid.org/0000-0001-5290-7702
}

\section{GT 08 - SAÚDE, MEIO AMBIENTE, PANDEMIA DA COVID 19 E SUAS CONSEQUÊNCIAS}

Resumo: A pandemia de COVID-19 transformou práticas cotidianas em todas as partes do mundo e impactou diversos setores da sociedade. Para tanto, propõe-se neste artigo uma reflexão e discussão sobre a pandemia de coronavírus e seus impactos gerais sobre a sociedade e a educação, evidenciando a abordagem ecopedagógica como uma possibilidade para reinterpretar esse cenário. Constatou-se que os impactos intensificados e ocasionados pelo coronavírus são imensuráveis, cuja disseminação da doença afetou drasticamente os processos de ensino e aprendizagem, o acesso à saúde, acentuando a falta de saneamanto básico e água tratada, especialmente para as classes mais pobres e em situação de vulnerabilidade. Contudo, em meio a essa crise, encontram-se lacunas e inquietações que conduzem o homem a refletir acerca de suas formas de vivência e posicionamento. Assim, a ecopedagogia, por meio do desenvolvimento da cidadania planetária, manifesta-se como uma ferramenta que pode auxiliar na reinterpretação do cenário atual, visto que ela é capaz indicar as rotas necessárias para entender, respeitar e valorizar mais satisfatoriamente o eu, o outro e o todo, o planeta. Palavras-Chaves: Ciência. Ecopedagogia. SARS-CoV-2.

\begin{abstract}
The COVID-19 pandemic has transformed everyday practices in all parts of the world and impacted different sectors of society. To this end, this article proposes a reflection and discussion about the coronavirus pandemic and its general impacts on society and education, showing the ecopedagogical approach as a possibility to reinterpret this scenario. It was found that the intensified impacts caused by the coronavirus are immeasurable, whose spread of the disease has drastically affected the teaching and learning processes, access to health, accentuating the lack of basic sanitation and treated water, especially for the poorest and most vulnerable classes. vulnerability situation. However, in the midst of this crisis, there are gaps and concerns that lead man to reflect on his ways of living and positioning. Thus, ecopedagogy, through the development of planetary citizenship, manifests itself as a tool that can assist in the reinterpretation of the current scenario, since it is able to indicate

\footnotetext{
1 Mestra em Ciências Ambientais. Pesquisadora do Grupo de Estudos e Pesquisas em Ciências Ambientais da Universidade Estadual do Oeste do Paraná. taiane nep@hotmail.com .

2 Profa Dra do Programa de Pós-Graduação em Ciências Ambientais da Universidade Estadual do Oeste do Paraná. terezinhalindino@gmail.com .
} 


\section{International Journal of Environmental}

\section{Resilience Research and Sciience (IJERRS)}

\section{Revista Internacional Resiliência Ambiental Pesquisa e Ciência Saciedade 5.0 Resiliência Ambiental}

ISSN 26753456

the necessary routes to understand, respect and value the self-more satisfactorily and the whole, the planet.

Keywords: Science. Ecopedagogy. SARS-CoV-2.

\section{INTRODUÇÃO}

Com a pandemia de COVID-19, causada pelo vírus SARS-CoV-2 (NETTO; CORRÊA, 2020) a sociedade global, que seguia seu curso normal, têm sua liberdade surripiada, junto à suspensão da vida cotidiana e modificação das relações sociais. Além do isolamento social, o coronavírus, trouxe medos, angústias, estresse e insegurança. Sobreviver a ele tornou-se um imperativo de vida.

O COVID-19, apresentou seus primeiros indícios na China e, rapidamente, difundiu-se pelo mundo, infectando e matando milhares de pessoas. A pandemia forçou a adoção de medidas e estratégias urgentes. Inúmeros países decretaram lockdown, fecharam suas fronteiras e controlaram a entrada e saída de pessoas (BITTENCOURT, 2020). As ameaças de contaminação causaram desdobramentos de ordem social, política e econômica, afetando direta ou indiretamente a vida de todos.

Não bastasse a fragilidade causada à sociedade e ao sistema econômico, a pandemia também gerou uma série de desdobramentos significativos nos processos educacionais. No Brasil, a educação, que antes já demostrava sinais de esgotamento pelo ensino tradicional, salas superlotadas e defasagens na capacitação docente, agora, teria que se adequar ao ensino remoto e à distância.

Mas, como é sabido, o processo de ensino e aprendizagem não reside na transmissão de conteúdos ou memorização deles. Pelo contrário, envolve, dentre outros fatores, a interação social, espaços e ferramentas adequadas, para a aquisição de conhecimentos teóricos e práticos. Em atendimento ao novo contexto, esses elementos receberam novas configurações no aprendizado remoto, numa escala sem precedentes, distanciando pessoas e saberes, pela atenuação da vivência cotidiana. 


\section{International Journal of Enviranmental}

\section{Resilience Research and Sriente (IJERRS)}

Revista Internacional Resiliência Ambiental Pesquisa e Ciência Sociedade 5.ๆ Resiliência Ambiental ISSN 26753456

Em virtude dessa conjuntura, a ecopedagogia, representa uma nova forma para enxergar e interpretar a pandemia. Porque a partir dela é possível estabelecer uma nova relação com as demais vidas e com o planeta. Isto é, poder-se-á refletir a própria realidade e ensejar a mudança, por meio de cada ação singular do homem, desenvolvida com sentido e emoção. Não há, pois, tempo a perder, já que de acordo com Gadotti (2003), a ecopedagogia é um movimento pedagógico, social e político, que têm o objetivo de transformar as relações humanas, ambientais e sociais, estabelecidas atualmente. Trata-se de um processo misterioso, mas não indecifrável!

Esse texto tem o objetivo de refletir e discutir a pandemia de coronavírus e seus impactos gerais sobre a sociedade e a educação, evidenciando a abordagem ecopedagógica como uma possibilidade para reinterpretar esse cenário.

\section{A EMERGÊNCIA DO CORONAVÍRUS COMO DOENÇA E SEUS IMPACTOS SOBRE AS EMOÇÕES}

O cenário da pandemia de coronavírus alterou profundamente a dinâmica global e as formas de viver do ser humano. Desde então, diferentes partes do mundo enfrentam uma série de desafios para conter sua disseminação, diminuir estatísticas de novos casos e encontrar um tratamento eficaz.

$O$ vírus SARS-CoV-2, pertencente à família Coronaviridae é classificado como encapsulado, RNA fita simples, capaz de infectar seres humanos. A sua transmissão acontece por meio de gotículas originárias da região oronasal de pessoas infectadas, pelo contato com superfícies e objetos contaminados (NETTO; CORRÊA, 2020). No entanto, muitas pessoas afetadas podem permanecer assintomáticas, por outro lado, em pacientes sintomáticos, a COVID-19 manifesta como principais sintomas clínicos: febre, tosse, infecções e lesões pulmonares (HUANG et al., 2020).

IJERRS - ISSN 26753456 - V.3, N.1, 2021 p. 91 
Como seu espectro clínico é muito amplo, em estágio avançado, os sintomas evoluem para pneumonia, podendo ainda, afetar o sistema gastrointestinal e nervoso central, rins, coração e fígado (LIU et al., 2020). Diante da ameaça do vírus e do insuficiente conhecimento científico sobre ele, a pandemia, constitui-se, sobremaneira, um desafio sanitário para a saúde pública.

No Brasil, os desafios para o controle do coronavírus se acentuam, pois, além da própria disseminação do patógeno, ainda tem-se a conjuntura da desigualdade social. Esta última, implica diretamente sobre a negligência de direitos fundamentais como a água e o saneamento básico. Não obstante, as moradias em situação de precariedade e aglomeração, especialmente nas regiões mais pobres do país, como periferias e palafitas, representam uma barreira ao enfrentamento da COVID-19.

Até o momento, no Brasil, já foram registrados cerca de 6.314 .740 casos confirmados e 172.833 mortes pela COVID-19³ (BRASIL, 2020). Esses números, apenas ratificam o afrouxamento de medidas básicas de proteção e a banalização da doença. Entretanto, não se pode negar que a doença, em um piscar de olhos, transformou as práticas diárias e, ao mesmo tempo, ofereceu, inclusive, a oportunidade para uma redescoberta individual e reflexão profunda, de quem somos, na verdade e como nosso modus operandi influencia a vida do outro.

Em linhas gerais, o contexto pandêmico, causa um mal-estar global, que dia após dia vai apagando a segurança e reduzindo as possibilidades estar juntos. $O$ distanciamento social entrelaça e articula um emaranhado de sentimentos, sensações e emoções, pelo seu caráter, concomitantemente, egoísta e solidário.

As tensões causadas pela pandemia geram alterações e sobrecarga no estado emocional dos indivíduos. Como o momento é de incerteza, as emoções tomam proporções maiores que o habitual, assim, o contexto assola pensamentos sobre 0 presente e o futuro, gerando uma sensação de impotência e exaustão física e mental.

\footnotetext{
${ }^{3}$ Dados atualizados até o dia 29 de novembro de 2020.
}

IJERRS - ISSN 26753456 - V.3, N.1, 2021 p. 92 
As incertezas sobre o controle da doença, sua severidade e o final da pandemia, são elementos de risco à saúde emocional de indivíduos ou grupos coletivos (ZANDIFAR; BADRFAM, 2020). O estado emocional permanece em consistência com essa nova conjuntura, podendo ser nocivo para muitas delas.

O momento representa um gatilho para uma crise ética e psicológica. Além da sociedade em geral, muitos profissionais da saúde, pela sua carga horária de trabalho excessiva e frustração, vem desenvolvendo diversos problemas psicológicos como estresse, ansiedade e depressão (SANTOS et al., 2020).

Entretanto, ao mesmo tempo, em que as doenças psíquicas e físicas se manifestam na população, para outras pessoas, as consequências da pandemia são mais profundas, marcando drasticamente sua história e, custando, em muitos casos, sua vida ou a violação do seu eu, do seu corpo. O amor e a fraternidade se tornam banais e insignificantes, frente ao desespero, nervosismo e preocupação. Com isso, os laços que deveriam se fortalecer, tornam-se ainda mais frágeis.

Nesse sentido, a violência doméstica, violência física, sexual e psicológica de crianças e adolescentes, abuso de álcool e drogas, suicídio, prostituição e outras, têm sua probabilidade de crescimento significativo, aumentadas pelo isolamento. Segundo Pereira et al., (2020) a sensação de pânico, devido à pandemia, desencadeia uma onda coletiva de medo, tristeza e culpa, ocasionando um extremo sofrimento psíquico.

Ademais, têm-se ainda, as dores e lutos, daqueles que perderam seus entes queridos e as experiências traumáticas, daqueles que sobreviveram à infecção do coronavírus. As alterações emocionais, cognitivas, afetivas e comportamentais se alteram à luz da indignação, de quem sequer pode despedir-se dignamente do seu semelhante, já que ritos funerários aumentam a chance de aglomeração e contágio.

Assim, evidencia-se a importância do fortalecimento da afetividade, solidariedade e humildade. Somos todos cidadãos terráqueos, por isso, é preciso se compreender como elementos que possuem um ciclo de vida que um dia chegará ao

IJERRS - ISSN 26753456 - V.3, N.1, 2021 p. 93 
fim, assim como qualquer outro componente vivo do planeta. Mais do que isso, é preciso, redimir o egocentrismo, desconstruindo a noção pejorativa de que o planeta é e está à disposição do homem e de que há um controle total sobre a natureza.

No decorrer dessa crise, em que os problemas sanitários impactam a vida social e as emoções, o medo, parece, ser um dos principais sentimentos do homem frente à pandemia, pelo fato de haver certa tensão diante do risco do vírus atingir a si próprio ou o futuro de todos nós. Além dele, há também a fragilidade, especialmente, por parte daqueles que estão à merce da saúde pública, que exibe constantemente o despreparo do país para esse momento. Esses sentimentos e demais correlatos, representam, portanto, uma forma para lidar com a complexidade do inesperado.

Contudo, esse contexto é um período significativo para o cultivo de sentimentos de otimismo, fé, amor, empatia pelo outro, valorização da vida e gratidão por estar vivo. É uma possibilidade para mudar a forma de viver e pensar as ações cotidianas. É preciso desvelar diferentes dimensões da realidade, se adaptar e transformar, trazendo a possibilidade de ser melhor para si, para o outro e para o planeta.

\section{O NOVO NORMAL E O NOVO VOCÊ: A HORA É DE REINVENTAR O MUNDO}

O que se impõe hoje, não se refere apenas ao período agudo que se vive. Diz, sobretudo, respeito às questões crônicas, que se encontram no âmago dos mais diversos contextos e setores, incluindo a educação. Ela não será a mesma após a pandemia, nem professores e alunos voltarão iguais. Isso é um fato e indica que a pandemia serviu para demonstrar o quão valioso é a presença, a interação.

A transformação das relações educacionais na pandemia, principalmente, na perspectiva da educação básica, torna evidente que haverá danos e prejuízos para muitos estudantes, especialmente aqueles advindos das classes vulneráveis. Com a

IJERRS - ISSN 26753456 - V.3, N.1, 2021 p. 94 


\title{
International Journal of Environmental
}

\section{Resilience Research and Science (IJERRS)}

Revista Internacional Resiliência Ambiental Pesquisa e Ciência Sociedade 5.0 Resiliência Ambiental ISSN 26753456

suspensão das aulas presenciais, os instrumentos tecnológicos e a internet se tornaram requisitos mínimos para o processo de aprendizagem não presencial.

Como poder-se-á pensar uma educação de qualidade para todos, se nem todos possuem as mesmas condições de acesso para estudar remotamente? O pior não é isso, há que se pensar sobre a segregação, que além da separação geográfica, isola (aqueles que já não se sentiam parte do todo) e aumenta a discrepância entre os diferentes grupos sociais. Nas palavras de Vieira e Ricci (2020, p. 4, grifo nosso):

\begin{abstract}
A situação gerada pelo COVID-19 evidenciou questões já existentes no ensino presencial, agravou estas situações, e, ainda, antecipou outras, demonstrando a necessidade urgente de investimento massivo, em estrutura física e pessoal, para que possamos honrar o que determina nossa Constituição. Trouxe à tona, também, de forma bastante escancarada, a necessidade de formação docente para este "reinventar da escola", uma vez posta, de forma que nos parece incontornável, a necessidade de finalmente invertermos a chave das práticas pedagógicas, promovendo um ensino ativo.
\end{abstract}

Nessas circunstâncias, experencia-se além da negação do direito básico à educação, uma exclusão dos sistemas educacionais por fatores de desigualdade social, questões de gênero, idade, deficiência e outros, onde também há uma grande tendência ao crescimento do abandono e evasão escolar. Mas, para além desses apontamentos, deve-se enxergar as outras facetas da pandemia, especialmente, ao concebê-la como uma oportunidade de refletir o entorno, a prática e o contexto.

Quando se fala em contexto, nota-se que este conceito remete aos interesses da espiral econômica e política mundial, onde países potenciais, num jogo incessante investem na busca por uma eventual vacina capaz de combater a evolução do vírus. De acordo com Cueto (2020), já existem inúmeras vacinas em teste clínico, em diversos estados brasileiros. O que mais chama a atenção, neste caso, é a desordem do processo, que vem menosprezando princípios como a efetividade e seguridade.

Como é sabido, a relação de muitas pessoas com as vacinas nem sempre foi harmônica, ou seja, a resistência, em relação a ela, fazem parte de sua própria evolução, assinalada pelos movimentos anti-vacina (POLAND; JACOBSON, 2001).

IJERRS - ISSN 26753456 - V.3, N.1, 2021 p. 95 
International Journal of Environmental

\title{
Resiliente Research and Srientes (IJERRS)
}

Revista Internacional Resiliência Ambiental Pesquisa e Ciência Sociedade 5.0 Resiliência Ambiental ISSN 26753456

Isso direciona os olhares para a negação da ciência e do conhecimento científico, que gira em torno das ideias do senso comum, da arte, religião e/ou outras, que tem sua funcionalidade expressada como discursos ideológicos em contextos específicos.

Além do entendimento desse panorama, outro ponto importante é o fato de acreditar ou não na ciência. Todos os indivíduos têm a possibilidade de decidir e, provavelmente, essa decisão pode afetar de forma positiva ou negativa o enfrentamento do coronavírus, já que cada ação singular reflete sobre a coletividade:

\begin{abstract}
Assim, importante dimensão que afeta a vacinação e a pandemia da COVID19 e potencializa a discussão sobre a relação indivíduo-sociedade está relacionada à (des)crença na ciência, tão importante na estruturação da tomada de decisão e na percepção de risco individual e coletivo (COUTO et al., 2020, p. 10)
\end{abstract}

No contexto da pandemia de coronavírus, a falta de informação da população tem levado a OMS e instituições governamentais e acadêmicas a desenvolverem plataformas capazes de interromper as fake news, evento que atua sobre a tomada de decisões, ações e entendimento de riscos, em relação ao vírus (ZAROCOSTAS, 2020). Atrelado a isso, a elevação dos profissionais de saúde como principais agentes de enfrentamento da COVID-19 e a desinformação das classes com menos acesso a canais de informação, favorecem a desvalorização das advertências e medidas de prevenção, estabelecidas pelos organismos responsáveis (COUTO et al., 2020).

Com isso, o vírus e sua ação, de modo geral, transformou a percepção social das pessoas, especialmente, acerca do imperativo de acreditar na ciência e na natureza, e mudando, sobretudo, a forma como as pessoas estão vivendo, acreditando e se posicionando diante das situações.

O caráter de recusa à ciência no Brasil têm se manifestado pelos números em relação à COVID-19. Negar os fatos significa entender que a ciência não representa uma forma rica de geração de tecnologias, produtos e conhecimentos, sendo esses elementos essenciais para o entendimento do momento em que o planeta perpassa.

IJERRS - ISSN 26753456 - V.3, N.1, 2021 p. 96 


\section{International Journal of Environmental}

\section{Resilience Ressarch and Science (IJERRS)}

Revista Internacional Resiliência Ambiental Pesquisa e Ciênncia Sociedade 5.D Resiliência Ambiental ISSN 26753456

A ciência nunca se movimentou tão rápido quanto agora. Cientistas do mundo inteiro geram constantemente diálogos científicos e reagem aos desafios desconhecidos, até alguns meses atrás. Tudo isso indica, ao nível nacional, a deficiência na questão de financiamento da pesquisa e de recursos disponíveis e, consequentemente, evidencia a importância do papel da ciência e das instituições de pesquisa como fonte de produção de conhecimento (PÁDUA, 2020).

Além destes aspectos, o posicionamento das pessoas ante a pandemia, é condicionada tanto pelas suas opiniões, quanto pelo meio, em uma interconexão entre eles. Numa perspectiva de reorientação dos olhares acerca da pandemia, da própria forma de concebê-la, a ecopedagogia emerge em favor de uma nova ética de pensamento e (re)interpretação do contexto atual. Apesar de estar em evolução, esse conceito vem sendo utilizado para a promoção de valores inerentes à construção de um planeta sustentável (GADOTTI, 2003).

A ecopedagogia permite novas possibilidades de ação e interpretação, a partir da cotidianidade. Por meio dela, o sentimento de pertença pode ser aprimorado, ainda mais no momento de crise planetária. A pandemia, exigiu de todos, uma "pausa" e isso veio a calhar como um tempo importante e necessário para a reflexão sobre as ações e relações estabelecidas. O cenário atual também proporcionou diferentes modos para pensar melhor sobre aquilo que viemos fazendo com a nossa vida, nos proporcionou tempo para ver, sentir, aprender e amar, mesmo que à distância.

De modo geral, ela se aplica a diferentes contextos e dimensões:

A Ecopedagogia é uma ferramenta que inclui em seu bojo discussões sobre política, economia, cultura, história e os processos de mudança pessoal, social, ambiental e cósmica, visando a promoção de um profundo sentimento de conexão com os outros e com a Terra, em todas as suas dimensões. Ela tem por objetivo fomentar um sentimento de responsabilidade compartilhada em relação a si mesmo, para com os outros e com o planeta (DONATO; SOUZA, 2016, p. 259, grifo nosso).

IJERRS - ISSN 26753456 - V.3, N.1, 2021 p. 97 
Dentro dessa conjuntura, a ecopedagogia também representa uma oportunidade para questionar o modelo de desenvolvimento econômico e social, mas também o modelo de vivência adotado pela sociedade capitalista. De acordo com Gadotti (2005), a sociedade sustenta-se pela fragmentação que divide brancos e negros, ricos e pobres, centro e periferia. No contexto da pandemia, essa diferença é torna-se mais visível, pela acentuação das desigualdades no Brasil. Assim, o desafio que se coloca nesse momento é a mudança da percepção das pessoas frente a pandemia. E, aqui emergem os princípios da ecopedagogia como uma proposta de fortalecimento da cidadania, isto é, a construção de uma cidadania mais planetária.

Esse conceito está ligado ao desenvolvimento de uma comunidade una, socialmente justa, sustentável e produtiva. "Cidadania planetária é uma expressão adotada para designar um conjunto de princípios, valores, atitudes e comportamentos fundados numa nova percepção da Terra" (GADOTTI, 2005, p. 23). Se pensada na prática, durante a pandemia de COVID-19, relaciona-se com a compreensão de que cada ação local, como uso da máscara, lavagem das mãos ou até mesmo a distância segura, é capaz de gerar impactos a nível global, é entender que tudo está interligado.

No entanto, essa proposta vai muito além da mudança de percepção, ela é participação, autonomia e democracia, tudo junto e, ao mesmo tempo (SOUZA; GADOTTI, 2011). A cidadania planetária pode colaborar com a reflexão sobre os direitos e deveres de cada pessoa, freando o alongamento de crise sanitária e reduzindo o aprofundamento da exclusão social.

No Brasil, o que têm se verificado é que a pandemia traz à tona a falta de conhecimento acerca dos conceitos básicos de cidadania, que pode prejudicar o combate ao coronavírus (ROCHA et al., 2020). Como não há cidadão com maior ou menor responsabilidade, exige-se, atualmente, a valorização da vida, o rompimento de discursos de exploração, exclusão e a incorporação da responsabilidade mútua.

IJERRS - ISSN 26753456 - V.3, N.1, 2021 p. 98 


\section{International Journal of Enviranmental}

\section{Resilience Research and Sriente (IJERRS)}

Revista Internacional Resiliência Ambiental Pesquisa e Ciência Sociedade 5.ๆ Resiliência Ambiental ISSN 26753456

Assim, a cidadania planetária pode resultar na transformação do ser humano, de suas relações e do mundo. Essa noção, ainda, fortalece a esperança de um amanhã melhor, de acreditar que é possível construir outro planeta, social e ambientalmente protegido, ético (GUTIÉRREZ; PRADO, 2013).

A ecopedagogia, atrelada ao contexto pandêmico atual eleva a importância do desenvolvimento coletivo, a transformação do eu, da relação estabelecida com o outro e, também, engloba a necessidade da justiça social no planeta. Parece claro que a proposta ecopedagógica, por meio da cidadania planetária, pretende o desenvolvimento de ações mais humanas, com significado, amor, compaixão e solidariedade. É o pensar e o agir com base no eu, no outro e tantos outros.

\section{CONSIDERAÇÕES FINAIS}

O atual surto de coronavírus, causador de COVID-19, assolou os locais mais remotos do planeta e junto a isso gerou e, vem gerando, diferentes impactos e discussões globais. Inúmeros países entraram em estado de calamidade pública ou situação de emergência, exigindo novos posicionamentos, assim como a adoção e aplicação de respostas ante a pandemia.

Ela transformou a forma de trabalhar, estudar e se comunicar; evidenciando fragilidades sociais, revelando, a negligência no acesso a direitos básicos, como: saneamento, moradia, educação e saúde. Nesse contexto, a condição social, no Brasil, também pôde ser compreendida como um fator determinante de vulnerabilidade à exposição do vírus. $\mathrm{O}$ isolamento trouxe à tona outros impasses que envolvem o aumento da violência, consequências na saúde mental, fome, pobreza e desemprego. Não se pode negar, que essa pandemia obrigou estados, empresas e pessoas a buscarem novos métodos para exercer suas atividades.

IJERRS - ISSN 26753456 - V.3, N.1, 2021 p. 99 
No caso da educação, independentemente do nível ou modalidade, alterou a prática pedagógica. Contudo, esse momento também trouxe uma nova ressignificação da educação, do papel do professor, da família, ferramentas didáticas, tecnologias de informação e comunicação, dentre outros. Não se pode negar que a pandemia causou medo, entretanto, representa um momento para repensar as condutas e ações.

Assim, tanto a forma de estudar, trabalhar e conviver precisam ser urgentemente repensadas pelo homem, assim como suas atitudes. Para que tanto egocentrismo e individualismo, se somos todos habitantes da mesma casa? Nessa linha de pensamento, o momento exige um novo posicionamento, a apropriação da responsabilidade, a mudança de hábitos e a adoção de novas formas de vivência, além do fortalecimento do respeito à autonomia da natureza. Requer, a remodelação de como estamos nos relacionando com o outro, este outro não se reduz apenas ao ser humano, mas ao outro animal, a outra planta as outras formas de vida.

A ecopedagogia, por meio da cidadania planetária, como ferramenta de transformação, indica os caminhos que podem ser trilhados, não apenas para uma vida mais significativa, mas para a busca do equilíbrio planetário. Ela refere-se a uma nova ética, uma nova ordem de reflexão e ação, para a uma vida mais saudável.

\section{REFERÊNCIAS}

BITTENCOURT, R. N. Pandemia, isolamento social e colapso global. Revista Espaço acadêmico, v. 19, n. 221, p. 168-178, 2020.

BRASIL. Coronavírus Brasil: painel coronavírus. 2020. Disponível em: <https://covid.saude.gov.br/> . Acesso em: 30 nov 2020.

COUTO, M. T.; BARBIERI, C. L. A.; MATOS, C. C. S. A. Considerações sobre o impacto da COVID-19 na relaçãoindivíduo-sociedade. 2020. Disponível em: <

https://preprints.scielo.org/index.php/scielo/preprint/download/1196/1819/1904>. Acesso em: 05 nov 2020.

CUETO, M. Covid-19 e a corrida pela vacina. História, ciências, saúde, v. 27, n. 3, p. 715-717, 2020.

DONATO, C. J.; SOUZA, G. P. O. Ecopedagogia: uma via para o desenvolvimento sustentável.

Colloquium Humanarum, v. 13, n. 1, p. 255-261, 2016.

IJERRS - ISSN 26753456 - V.3, N.1, 2021 p. 100 


\section{International Journal of Environmental}

\section{Resilience Research and Science (IJERRS)}

Revista Internacional Resiliência Ambiental Pesquisa e Ciênncia Sociedade 5.0 Resiliência Ambiental ISSN 26753456

GADOTTI, M. A Ecopedagogia como pedagogia apropriada ao processo da Carta da Terra. Revista de Educação Pública, v. 12, n. 21, p. 1-15, jun. 2003.

GADOTTI, M. Pedagogia da Terra e Cultura de Sustentabilidade. Revista Lusófona de Educação, v. 6, n. 1, p. 15-29, 2005.

GUTIÉRREZ, F.; PRADO, C. Ecopedagogia e cidadania planetária. 3.ed. São Paulo: Cortez, 2013.

HUANG, C.; WANG, Y.; LI, X.; REN, L.; ZHAO, J.; HU, Y.; ZHANG, L.; XU, G. F. J.; GU, X.; CHENG, Z.; YU, T.; XIA, J.; WEI, Y.; WU, W.; XIE, X.; YIN, W.; LI, H.; LIU, M.; XIAO, Y.; GAO, H.; GUO, L.; XIE, J.; WANG, G.; JIANG, R.; GAO, Z.; JIN, Q.; WANG, J.; CAO, B. Clinical features of patients infected with 2019 novel coronavirus in Wuhan, China. Lancet, v. 395, n. 1, p. 497-506, 2020.

LIU, C.; ZHOU, G.; LI, Y.; GARNER, L. V.; WATKINS, S. P.; CARTER, L. J.; SMOOT, J.; GREGG, A. C.; DANIELS, A. D.; JERVEY, S.; ALBAIU, D. Research and Development on Therapeutic Agents and Vaccines for COVID-19 and Related Human Coronavirus Diseases. ACS Central Science, v. 6, n. 1, p. 315-331, 2020.

NETTO, R. G. F.; CORRÊA, J. W. N. Epidemiologia do surto de doença por coronavírus (Covid-19). Revista Desafios, v. 7, n. 1, p. 18-25, 2020.

PÁDUA, J. P. C. V. Coronavírus, verdade e ciência: obstáculos e oportunidades para uma nova (velha) epistemologia. Revista confluências, v. 22, n. 2, p. 79-105, 2020.

PEREIRA, M. D.; OLIVEIRA, L. C.; COSTA, C. F. T.; BEZERRA, C. M. O.; PEREIRA, M. D.;

SANTOS, C. K. A. A pandemia de COVID-19, o isolamento social, consequências na saúde mental e estratégias de enfrentamento: uma revisão integrativa. Research, society and development, v. 9, n. 7, p. 1-35, 2020.

POLAND, G.; JACOBSON, R. M. Understanding those who do not understand: a brief review of antivaccine movement. Vaccine, v. 19, n. 19, p. 2440-2445, 2001.

ROCHA, C. G.; AZEVEDO, D.; ROCHA, L. Novos caminhos para a cidadania: uma reflexão sobre o Brasil e a COVID 19. In: CASTRO, D.; DAL SENO, D.; POCHMANN, M. Capitalismo e a covid-19: um debate urgente. São Paulo: ABET, 2020. p. 199-204.

SANTOS, W. A.; BERETTA, L. L.; LEITE, B. S.; SILVA, M. A. P.; CORDEIRO, G. P.; FRANÇA, E. M. O impacto da pandemia da COVID-19 na saúde mental dos profissionais de saúde: revisão integrativa. Research, society and development, v. 9, n. 8, p. 1-29, 2020.

SOUZA, E.; GADOTTI, M. Novos tempos da Educação em Osasco. In: PADILHA, P. R.; FAVARÃO, M. J.; MORRIS, E.; MARINE, L. (Orgs.) Educação para a Cidadania Planetária: currículo intertransdisciplinar em Osasco. São Paulo: Editora e Livraria Instituto Paulo Freire, 2011.

VIEIRA, L.; RICCI, M. C. C. A educação em tempos de pandemia: soluções emergenciais pelo mundo. Florianópolis: Observatório do Ensino Médio em Santa Catarina, 2020.

ZANDIFAR, A.; BADRFAM, R. Iranian mental health during the COVID-19 epidemic. Asian Journal of Psychiatry, v. 51, n. 1, p. 101990-101990, 2020.

ZAROCOSTAS, J. How to fight an infodemic. The Lancet, v. 395, n. 10225, p. 676-676, 2020.

IJERRS - ISSN 26753456 - V.3, N.1, 2021 p. 101 